\title{
The relationship between educational level and bone mineral density in postmenopausal women
}

\author{
Ali Gur*1, Ayşegül Jale Sarac², Kemal Nas ${ }^{3}$ and Remzi Cevik ${ }^{3}$
}

\author{
Address: ${ }^{1}$ Physical Medicine and Rehabilitation, Medical Faculty, Dicle University, Diyarbakir, Turkey, ${ }^{2}$ Physical Medicine and Rehabilitation, \\ Medical Faculty, Dicle University, Diyarbakir, Turkey and ${ }^{3}$ Physical Medicine and Rehabilitation, Medical Faculty, Dicle University, Diyarbakir, \\ Turkey \\ Email: Ali Gur* - alig@dicle.edu.tr; Ayșegül Jale Sarac - sarac@dicle.edu.tr; Kemal Nas - knas@dicle.edu.tr; Remzi Cevik - ftremzi@dicle.edu.tr \\ * Corresponding author
}

Published: 06 September 2004

BMC Family Practice 2004, 5:18 doi:10.1186/147|-2296-5-18
Received: 19 February 2004

Accepted: 06 September 2004

This article is available from: http://www.biomedcentral.com/I47/-2296/5//8

(C) 2004 Gur et al; licensee BioMed Central Ltd.

This is an open-access article distributed under the terms of the Creative Commons Attribution License (http://creativecommons.org/licenses/by/2.0), which permits unrestricted use, distribution, and reproduction in any medium, provided the original work is properly cited.

\begin{abstract}
Background: This study describes the influence of educational level on bone mineral density (BMD) and investigating the relationship between educational level and bone mineral density in postmenopausal women.
\end{abstract}

Methods: A total of 569 postmenopausal women, from 45 to 86 years of age (mean age of 60.43 \pm 7.19 years) were included in this study. A standardized interview was used at the follow-up visit to obtain information on demographic, life-style, reproductive and menstrual histories such as age at menarche, age at menopause, number of pregnancies, number of abortions, duration of menopause, duration of fertility, and duration of lactation. Patients were separated into four groups according to the level of education, namely no education (Group I with 209 patients), elementary (Group 2 with 222 patients), high school (Group 3 with 79 patients), and university (Group 4 with 59 patients).

Results: The mean ages of groups were $59.75 \pm 7.29,61.42 \pm 7.50,60.23 \pm 7.49$, and $58.72 \pm 7.46$, respectively. Spine BMD was significant lower in Group I than that of other groups $(p<0.05)$. Trochanter and ward's triangle BMD were the highest in Group 4 and there was a significant difference between Group I and 4 ( $p<0.05)$. The prevalence of osteoporosis showed an inverse relationship with level of education, ranging from $18.6 \%$ for the most educated to $34.4 \%$ for the no educated women $(p<0.05)$. Additionally, there was a significant correlation between educational level and spine BMD $(r=0.20, p<0.01)$, trochanter BMD $(r=0.13, p<0.01)$, and ward's BMD $(r$ $=0.14, \mathrm{p}<0.01$ ).

Conclusions: The results of the study suggest that there is a significant correlation between educational level and BMD. Losses in BMD for women of lower educational level tend to be relatively high, and losses in spine and femur BMD showed a decrease with increasing educational level.

\section{Background}

Osteoporosis has recently been recognized as a major public health problem by some governments and health care providers. In the European community, the number of men and women aged 65 years of older will increase steadily and the most dramatic changes will occur in the 
very elderly, in whom the incidence of osteoporotic fracture is greatest [1]. As the populations gets older, morbidity, mortality and financial costs attributed to osteoporosis are expected to rise. The economic costs related to osteoporotic fractures are substantial and will almost certainly increase further unless effective preventive interventions are widely implemented [2].

Peak bone mass is achieved soon after puberty, and bone is lost with various "insults", including ageing and postmenopausal changes. Factors influencing peak bone mass and loss range from nutrition, to lifestyle, to certain medical disorders. Educational level may also have an effect on bone mineral density since there is relationship between educational level and reproductive factors such as pregnancy and lactation and other lifestyle factors [37].

In developed countries a higher prevalence of most chronic diseases has been recognized among lower socio economic levels and in less educated subjects [8-14]; however, only a few and conflicting data are available for osteoporosis [15-18].

Since many risk factors for osteoporosis, such as diet, deficiency of trace minerals, reproductive factors, inactivity and tobacco use, are lifestyle variables related to social and cultural background [18-25], the influence of formal educational level on bone mineral density [BMD], together with establishment of a relationship between formal educational level and bone mineral density in postmenopausal women are the main concern of this study.

Patients were compared according to years of formal education. We used formal education because it may be regarded as a composite or surrogate variable for overall socioeconomic status [10], and level of education [years of completed education) allows comparison between countries more readily than other socioeconomic indicators [13].

Purpose of this study was to evaluate the influence of formal education on BMD and investigating the relationship between educational level and bone mineral density in the postmenopausal women.

\section{Methods}

In Department of Physical Medicine and Rehabilitation, of the total 701 consecutive women screened, 132 were excluded. This study was undertaken in Dicle University, Diyarbakir, Turkey. The study protocol was reviewed and approved by the Dicle University Ethics Committee, and informed consent was obtained from all participants. A detailed history was taken from each woman including relevant life-style parameters and risk factors, and their weight and height measurements were recorded. The following exclusion criteria were applied for further analyses: (1) fractures after the age of 25; (2) menopause before the age of 40; (3) amenorrhoea greater than 6 months; (4) chronic conditions affecting bone density; (5) any use of corticosteroids.

A total of 569 postmenopausal women, at 45 to 86 years of age (mean age of $60.43 \pm 7.19$ years) were considered. $\mathrm{BMD}$ of the spine and hip (neck, trochanter, and ward's triangle) were measured by dual-energy $\mathrm{x}$-ray absorptiometry (NORLAND, 6938CE, New York, USA). According to the WHO [26] osteoporosis was defined as a lumbar BMD value more than $2.5 \mathrm{SD}$ below the T-score, corresponding to $0.759 \mathrm{~g} / \mathrm{cm}^{2}$ [27]. The variation coefficient for consecutive determinations on spine and femur images in our laboratory was $1.9 \%$ at the lumbar spine and $1.6 \%$ at the femur region. All spinal scans were reviewed for evidence of vertebrae with collapse or focal sclerosis by an experienced radiologist.

In order to standardize the procedure, the patients all answered the same specially developed questionnaire supervised by the doctor (revised from the MEDOS Form) [28]. A standardized interview was used at the follow-up visit to obtain information on demographic, life-style, reproductive and menstrual histories such as age at menarche, age at menopause, number of pregnancies, number of abortions, duration of menopause, duration of fertility, and duration of lactation.

The level of education is categorized in four groups according to the number of school years and the highest qualification received; no education (Group $1=209$ patients), elementary ( 8 years or less, Group $2=222$ patients), high school (9-11 years, Group $3=79$ patients), and university ( 12 years or more, Group $4=59$ patients). Body mass index (BMI; weight $/$ height $^{2}$ ) was obtained through height and weight measurements by using a wall-mounted ruler and a digital scale.

Recent dietary calcium intake (past 12 months) was assessed using standardized food models to estimate portion sizes [24]. Dietary calcium intakes were analyzed in two groups as inadequate $(<500 \mathrm{mg} /$ day $)$ and adequate (500-1000 mg/day) [25]. The number of drinks consumed per week in the past 30 days, was used as the measure of current alcohol consumption (never use, very rare, frequently). Women who had smoked at least ten cigarettes per day during the five postmenopausal years were classified as smokers [25]. All patients classified, in terms of their reported current and life long smoking, into such group: 1) never use, 2) less than 1 packet, 3) 1-2 packet, and 3 ) more than 2 packets per day. They were also classified, in terms of their reported current and life-long 
caffeine use, into such groups: 1) never use, 2) 2 or below cup caffeinated coffee per day, 3) 3 or above cups caffeinated coffee per day. Physical activity is assessed by inquiring about the reported number of 20-min sessions of leisure-time physical activity per week and physically active behavior is defined as participation in more than two sessions per week; job-related physical exercise is not taken into account.

\section{Statistical analyses}

The statistical analyses were carried out with the SPSS/ PCprogram. Differences in proportions for categorical variables were tested by chi-square test. The data are expressed as means \pm SD. Statistical significance was tested using one way-ANOVA test and post-hok Bonferroni test for comparison of different groups. Pearson correlation test were computed to measure the association between the variables studied. The statistical significant set if the pvalue was less than 0.05 .

\section{Results}

Their reproductive and demographic characteristics are shown in Table 1 . When comparing the adequate calcium intake, the most educated women showed a statistically significant higher percentage than that of the other groups $(\mathrm{p}<0.05)$. The mean ages of groups were $59.75 \pm 7.29$, $61.42 \pm 7.50,60.23 \pm 749$, and $58.72 \pm 7.46$, respectively. There was no significant difference among all groups with respect to age, $\mathrm{BMI}$, age at menarche, age at menopause, and duration of menopause $(\mathrm{p}>0.05)$ (Table 2$)$.

Number of abortions was higher in group 1 and 2 than those of group 3 and $4(\mathrm{p}<0.05)$. There was no significant difference with respect to number of pregnancies and duration of lactation between group 3 and 4 while there was a significant difference among other groups ( $\mathrm{p}<$ 0.05 ), and number of pregnancies and duration of lactation were found to be the highest in Group 1 and 2 . Number of pregnancies and duration of lactation in Group 1 were $7.11 \pm 3.38$ and $133.23 \pm 54.34$ months and in Group 2 were $4.93 \pm 3.61$ and $93.62 \pm 50.66$ months (Table 2).

Spine BMD was significant lower in Group 1 than that of other groups $(\mathrm{p}<0.05)$. Trochanter and ward's BMD were the highest in Group 4 and there was a significant difference between Group 1 and $4(\mathrm{p}<0.05)$. The prevalence of osteoporosis showed an inverse relationship with level of education, ranging from $18.6 \%$ for the most educated to $34.4 \%$ for the no educated women $(\mathrm{p}<0.05)$ (Table 3$)$.

Additionally, there was a significant correlation between educational level and spine $\operatorname{BMD}(\mathrm{r}=0.20, \mathrm{p}<0.01)$, trochanter BMD ( $\mathrm{r}=0.13, \mathrm{p}<0.01)$, and ward's BMD $(\mathrm{r}=$ $0.14, \mathrm{p}<0.01)$ but wasn't neck BMD $(\mathrm{r}=-0.02, \mathrm{p}>0.05)$.

\section{Discussion}

The health care costs, morbidity and mortality excess related to osteoporotic fractures are a major health problem in western countries $[29,30]$. In order to reduce these medical, social and economic burdens, which are expected to rise in forthcoming years, there is a need for preventive strategies based on health promotion campaigns [31]. To change health behavior related to modifiable risk factors for osteoporosis and to design targeted and more effective health messages [32], the programs have to take into account the socioeconomic and cultural background of the population strata in which the risk for osteoporosis is particularly prominent [15].

Although mechanisms of association between education and osteoporosis remain partly unexplained, most of the risk factors examined have shown distinct trends according to educational level. Although educational level may be an imperfect measure for socio economic status, many studies have clearly established that this marker acts as a good predictor not only for most chronic diseases $[10,11,14]$ but also for many related risk factors $[22,23]$.

In a study by La Vecchia et al., they found that education is a strong determinant of several chronic conditions, and the pattern of health care utilization also varied extensively according to education [11].

Varenna et al. evaluated 6160 postmenopausal women referred for their first densitometric evaluation and they found age at menarche, past exposure to oral contraceptives, prevalence of chronic diseases, physical activity, overweight and smoking showed significant trends according to years of education [15]. Also, as they had a cohort of postmenopausal women as the study group, they could show differences in the prevalence of osteoporosis among educational classes and the protective role played by increases in formal education.

The present study showed that there was no significant difference among all groups with respect to age, BMI, age at menarche, age at menopause, and years since menopause. But there were statistically significant differences among groups in respect to number of pregnancies, duration of lactation, bone mineral density and percentage of osteoporosis.

The comparison with studies performed in other countries can be misleading since eating habits are strongly influenced by ethnic and geographical backgrounds [7]. The meaning of the lower calcium intake observed in the least educated women could be referred to a real difference, taking into account the low sensitivity of the questionnaire used to assess calcium intake. During pregnancy and lactation the growing fetal and neonatal skeletons 
Table I: Values for various reproductive and personal characteristics among 569 women screened for osteoporosis according to education level

\begin{tabular}{|c|c|c|c|c|}
\hline Variable & $\begin{array}{l}\text { No Education } \\
\text { (Group I = 209) }\end{array}$ & $\begin{array}{l}\text { Elementary } \\
\text { (Group } 2=222 \text { ) }\end{array}$ & $\begin{array}{l}\text { High school } \\
\text { (Group } 3=79 \text { ) }\end{array}$ & $\begin{array}{l}\text { University } \\
\text { (Group } 4=59 \text { ) }\end{array}$ \\
\hline \multicolumn{5}{|c|}{ Menstrual cycle pattern, (\%) } \\
\hline Regular cycles & $159(76)$ & $|5|(68)$ & $66(84)$ & $43(73)$ \\
\hline Irregular cycles & $50(24)$ & $71(22)$ & $13(16)$ & $16(27)$ \\
\hline \multicolumn{5}{|c|}{ Menopausal status, (\%) } \\
\hline Natural & $|7|(82)$ & $189(85)$ & $72(91)$ & $40(69)$ \\
\hline latrogenic & $38(18)$ & $33(15)$ & 7 (9) & $19(31)$ \\
\hline \multicolumn{5}{|c|}{ Premenopausal HRT, (\%) } \\
\hline Never use & $195(93)$ & $195(88)$ & $59(75)$ & $51(86)$ \\
\hline Ever use & $14(7)$ & $27(12)$ & $20(25)$ & $8(14)$ \\
\hline \multicolumn{5}{|c|}{ Postmenopausal HRT, (\%) } \\
\hline Never use & $201(96)$ & $203(91)$ & $63(79)$ & $52(88)$ \\
\hline Ever use & $8(4)$ & $19(9)$ & $16(21)$ & $7(12)$ \\
\hline \multicolumn{5}{|c|}{ Physical daily activity, (\%) Childhood } \\
\hline Inactivity & $6(3)$ & $33(15)$ & $14(18)$ & $8(14)$ \\
\hline Mild activity & $100(48)$ & $118(53)$ & $59(75)$ & $32(54)$ \\
\hline Serious activity & $103(49)$ & $71(32)$ & $6(7)$ & $19(32)$ \\
\hline \multicolumn{5}{|l|}{ Adolescent } \\
\hline Inactivity & $8(4)$ & $35(16)$ & $15(19)$ & $9(15)$ \\
\hline Mild activity & $60(29)$ & $105(47)$ & $54(68)$ & $19(32)$ \\
\hline Serious activity & $|4|(67)$ & $82(37)$ & $10(13)$ & $31(53)$ \\
\hline \multicolumn{5}{|l|}{ Adult } \\
\hline Inactivity & $56(27)$ & $83(37)$ & $38(48)$ & $22(37)$ \\
\hline Mild activity & $94(45)$ & $97(44)$ & $36(46)$ & $21(36)$ \\
\hline Serious activity & $59(28)$ & 42 (19) & $5(6)$ & $16(26)$ \\
\hline \multicolumn{5}{|c|}{ Calcium intake, (\%) } \\
\hline Adequate & $102(49)$ & $107(48)$ & $36(46)$ & $45(76)^{*}$ \\
\hline Inadequate & $107(5 \mathrm{I})$ & $115(52)$ & $43(54)$ & $14(24)$ \\
\hline \multicolumn{5}{|l|}{ Smoking, (\%) } \\
\hline Never use & $203(97)$ & $185(83)$ & $59(75)$ & $40(69)$ \\
\hline$<$ I packet & $4(2)$ & $18(8)$ & $6(7)$ & $9(15)^{\prime}$ \\
\hline I-2 packet & $2(1)$ & $9(4)$ & $10(13)$ & I (2) \\
\hline$>2$ packet & - & $10(5)$ & $4(5)$ & $8(14)$ \\
\hline \multicolumn{5}{|l|}{ Coffee, (\%) } \\
\hline Never use & $117(56)$ & $102(46)$ & $43(54)$ & $20(34)$ \\
\hline 2 or below cup & $88(42)$ & $85(38)$ & $20(25)$ & $23(39)$ \\
\hline 3 or above cup & $4(2)$ & $35(16)$ & $16(21)$ & $16(26)$ \\
\hline \multicolumn{5}{|l|}{ Alcohol, (\%) } \\
\hline Never use & $203(97)$ & $204(92)$ & $64(8 I)$ & $40(68)$ \\
\hline Very rare & $2(1)$ & $12(5)$ & $10(13)$ & $14(24)$ \\
\hline Frequently & $4(2)$ & $6(3)$ & $5(6)$ & $5(8)$ \\
\hline
\end{tabular}

*Significant different from other groups $(p<0.05)$.

make major demands for calcium, respectively. There is good evidence now that during lactation a substantial part of this calcium demand is mobilized from the maternal skeleton even despite high dietary calcium. This effect could be especially important with multiple pregnancies and extended lactation.

Magnus et al. undertook a random sample of 1514 Norwegian women and men to investigate knowledge of osteoporosis and attitudes towards methods for preventing this disease, and they concluded that in both men and women, increased knowledge of osteoporosis was correlated to a high level of education [33].

In several studies, authors have found that reproductive history has an inverse relation to bone density [3-6,3441]. The bone density is adversely affected by both high rate of live birth and long period of breast feeding, common in the region where this study was carried out. The lower birth rate and short period of breast feeding found 
Table 2: Comparison of reproductive characteristics of 569 women according to education level

\begin{tabular}{lcccc}
\hline & No Education & Elementary & High school & University \\
\hline Age (years) & $59.75 \pm 7.29$ & $61.42 \pm 7.50$ & $60.23 \pm 7.49$ & $58.72 \pm 7.46$ \\
Body Mass Index & $27.18 \pm 5.14$ & $28.23 \pm 5.63$ & $27.72 \pm 6.14$ & $28.45 \pm 5.56$ \\
Age at menarche (years) & $13.77 \pm 1.36$ & $13.75 \pm 1.28$ & $14.09 \pm 0.83$ & $13.22 \pm 1.38$ \\
Age at menopause (years) & $45.26 \pm 5.57$ & $45.22 \pm 6.72$ & $47.25 \pm 4.69$ & $45.38 \pm 5.25$ \\
Duration of fertility (years) & $31.48 \pm 5.73$ & $31.47 \pm 6.79$ & $33.25 \pm 4.81$ & $32.16 \pm 5.61$ \\
Duration of menopause (years) & $14.49 \pm 7.8$ & $13.20 \pm 8.17$ & $12.02 \pm 8.02$ & $12.41 \pm 8.73$ \\
Number of abortions & $1.31 \pm\left. 1.5\right|^{\mathrm{b}, \mathrm{c}}$ & $0.94 \pm 1.64$ & $0.51 \pm 1.17$ & $0.19 \pm 0.54$ \\
Number of pregnancies & $7.11 \pm 3.38^{\mathrm{a}, \mathrm{b}, \mathrm{c}}$ & $4.93 \pm\left. 3.6\right|^{\mathrm{d}, \mathrm{e}}$ & $2.27 \pm 1.91$ & $2.29 \pm 1.39$ \\
Duration of lactation (months) & $133.2 \pm 54.3^{\mathrm{a}, \mathrm{b}, \mathrm{c}}$ & $93.62 \pm 50.66^{\mathrm{d}, \mathrm{e}}$ & $45.76 \pm 38.83$ & $57.77 \pm 35.36$ \\
\hline
\end{tabular}

Values are shown as mean \pm standard deviation (SD) for all variables.

aSignificant different from elementary group, b Significant different from high school group, cSignificant different from university group, ${ }^{d}$ Significant different from high school group, and e Significant different from university group $(p<0.05)$.

Table 3: Comparisons of bone mineral density of 569 women according to education level

\begin{tabular}{ccccc}
\hline & No Education & Elementary & High school & University \\
\hline L2-4 BMD & $0.62 \pm 0.29 \mathrm{a}, \mathrm{b}, \mathrm{c}$ & $0.74 \pm 0.19$ & $0.77 \pm 0.17$ & $0.76 \pm 0.33$ \\
Femoral Neck BMD & $0.64 \pm 0.19$ & $0.61 \pm 0.24$ & $0.62 \pm 0.24$ & $0.64 \pm 0.21$ \\
Trochanter BMD & $0.49 \pm 0.18 \mathrm{c}$ & $0.53 \pm 0.19$ & $0.56 \pm 0.16$ & $0.61 \pm 0.12$ \\
Ward's triangle BMD & $0.45 \pm 0.17 \mathrm{c}$ & $0.49 \pm 0.18$ & $0.49 \pm 0.20$ & $0.58 \pm 0.10$ \\
Osteoporosis (\%) & $72(34.4)^{\mathrm{a}, \mathrm{b}, \mathrm{c}}$ & $62(27.9)^{\mathrm{d}, \mathrm{e}}$ & $17(21.5)$ & $1 \mathrm{I}(18.6)$ \\
\hline
\end{tabular}

Values are shown as mean \pm standard deviation (SD) for all variables except percentage of osteoporosis.

aSignificant different from elementary group, b Significant different from high school group, cSignificant different from university group ( $p<0.05$ ).

with the group having university or high school degree, may suggest that both birth rate and the breast feeding period may be associated with educational level. Furthermore, the calcium intake in the group with highest educational level was also found to be considerably higher than that of the other groups. The higher BMD values found with the group of highest educational level, may be attributed to the sufficient amount of calcium intake as was the case with this group

Though the effect of formal educational level on bone mineral density has not yet been well established, the above findings may suggest some hypothetical comments. The findings of this study imply that osteoporosis which is related to bone mineral density, may be related to the educational level and the risks due to higher birth rate, excessive breast-feeding and insufficient calcium intake, and may be controlled through an improvement in educational level.

Because of several limitations, caution must be exercised in interpreting the results of our study. Except for densitometric assessment, the results depend on self-reports. Even though self-report diagnoses have been shown to be valid [6], the level of formal education could bias the report about habits and health practices. Moreover, the sample was not randomly selected and it cannot be con- sidered representative of postmenopausal women in Turkey.

Similar studies are recommended to be carried out in different communities in an effort to confirm whether these findings can be generalized or yield a more complete insight into pathogenetic mechanisms. The knowledge of which population strata may be at greater risk of osteoporosis should be considered carefully for the purpose of health care planning and preventive strategies, making it possible to design tailored and culturally appropriate public health intervention programs.

The protective role played by educational level, which increases with the years of formal education, could be due to other overall determinants can be indirectly inferred from our data, such as a better health status, a more positive attitude to taking drugs and a more efficient use of health care resources. All these determinants can be considered in the light of a greater concern by the women about their own health status, probably related to a different impact of health promotion messages.

\section{Conclusions}

In conclusion, the results of the study suggest that there is a significant correlation between educational level and $\mathrm{BMD}$, and shows differences in the prevalence of oste- 
oporosis among educational classes and the protective role played by increases in formal education. Losses in BMD for women of lower educational level tend to be relatively high, and losses in spine and femur BMD showed a decrease with increasing educational level. Although mechanisms of association between education and low bone mineral density remain partly unexplained, most of the risk factors examined have shown distinct trends according to educational level.

\section{Competing interests}

None declared.

\section{Financial competing interests}

None declared.

\section{Authors' contributions}

AG participated in the design of the study and performed the statistical analyses.

AJS conceived of the study, and participated in its design and coordination.

$\mathrm{KN}$ and RC participated in the sequence alignment and screened of subjects.

\section{All authors read and approved the final manuscript.}

\section{References}

I. Compston JE, Papapoulos SE, Blanchard F: Report on osteoporosis in the European community: current status and recommendations for the future. Osteoporosis Int 1998, 8:531-34.

2. Gabriel SE, Tosteson AN, Leibson CL, Crowson CS, Pond GR, Hammond CS, Melton LJ 3rd: Direct medical costs attributable to osteoporotic fractures. Osteoporosis Int 2002, 13:323-30.

3. Chan GM, Slater P, Ronald N, Roberts CC, Thomas MR, Folland D, Jackson R: Bone mineral status of lactating mothers of different ages. Am J Obstet Gynecolo 1982, I44:438-4I.

4. Gur A, Nas K, Cevik R, Sarac A, Ataoğlu S, Karakoc M: Influence of number of pregnancies on bone mineral density in postmenopausal women at different age groups. J Bone Miner Metab 2003, 2 I (4):23I-24I.

5. Gur A, Cevik R, Nas K, Saraç AJ, Ataoğlu S, Karakoç M, Can A, Gürkan $F$ : The influence of duration of breastfeeding on bone mass in postmenopausal women of different age groups. Int J Clin Pract 2003, 57(2):82-86.

6. Colditz GA, Martin P, Stampfer MJ, Willett WC, Sampson L, Rosner $\mathrm{B}$, Hennekens $\mathrm{CH}$, Speizer FE: Validation of questionnaire information on risk factors and disease outcome in a prospective cohort study of women. Am J Epidemiol 1986, I 23:894-900.

7. Werner P, Olchovsky D, Shemi G, Vered I: Osteoporosis healthrelatedbehaviors in Secular and Orthodox Israeli Jewish Women. Maturitas 2003, 46(4):283-94.

8. Syme SL, Berkman LF: Social class susceptibility and sickness. Am J Epidemiol 1976, 104: I-8.

9. Lundberg O: Class and health: comparing Britain and Sweden. Soc Sci Med 1986, 23:5 I I-7.

10. Pincus T, Callahan LF, Burkhauser RV: Most chronic diseases are reported more frequently by individuals with fewer than 12 years of formal education in the age 18-64 United States population. J Chron Dis 1987, 40:865-74.

II. La Vecchia C, Negri E, Pagano R, Decarli A: Education, prevalence of disease and frequency of health care utilization. J Epidemiol Community Health 1987, 41:161-5.
12. Diderichsen F: Health and social inequities in Sweden. Soc Sci Med 1990, 31:359-67.

13. Lahelma $E$, Valkonen $T$ : Health and social inequities in Finland and elsewhere. Soc Sci Med 1990, 3 I:257-65.

14. Helmert $U$, Shea $S$ : Social inequalities and health status in Western Germany. Public Health 1994, 108:34I-56.

15. Varenna M, Binelli L, Zucchi F, Ghiringhelli D, Galazzi M, Sinigaglia L: Prevalence of osteoporosis by educational level in a Cohort of postmenopausal women. Osteoporosis Int 1999, 9:236-4I.

16. Del Rio Barquero L, Baures MR, Segura JP: Bone mineral density in two different socio-economic population groups. Bone Miner 1992, 18:159-68.

17. Elliot JR, Gilchrist NL, Wells JE: The effects of socioeconomic status on bone density in a male Caucasian population. Bone 1996, I 8:37I-3.

18. Popkin BM, Haines PS, Reidy KC: Food consumption trend of US women:patterns and determinants between 1977 and 1985 . Am J Clin Nutr 1989, 49:1307-19.

19. Gur A, Colpan L, Nas K, Cevik R, Sarac AJ, Erdogan F, Düz MZ: the role of trace minerals in the pathogenesis of postmenopausal osteoporosis and a new effect of calcitonin. J Bone Miner Metab 2002, 20:39-43.

20. Tappurainen M, kröger H, Saarikoski S, Honkanen R, Alhava E: The effect of previous oral contraceptive use on bone mineral density in perimenopausal women. Osteoporosis Int 1994, 4:93-8.

21. Sinclar HK, Bond CM, Taylor RJ: Hormone replacement therapy: a study of womens knowledge and attitudes. $\mathrm{Br} J \mathrm{Gen}$ Pract 1993, 43:365-70.

22. Shea S, Stein AD, Basch CE, Lantigua R, Maylahn C, Strogatz DS, Novick $L$ : Independent associations of educational attaintment and ethnicity with behavioral risk factors for cardiovascular disease. Am J Epidemiol 1991, I 34:567-82.

23. Winkleby MA, Fortmann SP, Barrett DC: Social class disparities in risk factors for disease: eight-year prevalence patterns by level of education. Prev Med 1990, I2: I- 12.

24. Ford ES, Merritt RK, Heath GW, Powell KE, Washburn RA, Kriska A, Haile G: Physical activity behaviors in lower and higher socioeconomic statuspopulations. Am J Epidemiol 1991, 133: I246-56.

25. Gur A, Nas K, Kayhan O, Atay MB, Akyuz G, Sindal D, Aksit R, Oncel S, Dilsen G, Cevik R, Gunduz OH, Ersoy Y, Altay Z, Ozturk C, Akkus S, Senocak O, Kavuncu V, Kirnap M, Tekeoglu I, Erdogan F, Sarac AJ, Demiralp L, Demirkesen A, Adam M: The relation between tooth loss and bone mass in postmenopausal osteoporotic women in Turkey: a multicenter study. J Bone Miner Metab 2003, 2I(I):43-47.

26. WHO Study Group: Osteoporosis. In: Assessment of fracture risk and its application to screening for postmenopausal osteoporosis. Technical report series 843 Geneva: WHO; 1994:2-25.

27. Varenna M, Binelli L, Zucchi F, Beltrametti P, galazzi M, Sinigaglia L: Is the metatarsal fracture in postmenopausal women an osteoporotic fracture? A cross-sectional study on II 3 cases. Osteoporosis Int 1997, 7:558-63.

28. Johnell O, Gullberg B, Kanis JA, Allander E, Elffors L, Dequeker J, Dilsen G, Gennari C, Lopes Vaz A, Lyritis G: Risk factors for hip fracture in European women: the MEDOS Study. Mediterranean Osteoporosis Study. J Bone Miner res 1995, I O(II): I802-I5.

29. Cooper C, Atkinson EJ, Jacobsen SJ, O'Fallon WM, Melton LJ 3rd: Population based study of survival after osteoporotic fracture. Am J Epidemiol 1993, I37: I00 I-5.

30. Chrischilles E, Shireman T, Wallace R: Costs and health effects of osteoporotic fractures. Bone 1994, 15:377-86.

3I. Cooper C, Campion G, Melton LJ III: Hip fractures in the elderly: aworld-wide projection. Osteoporosis Int 1992, 2:285-9.

32. Plimpton S, Root J: Materials and strategies that work in low literacy health communication. Public Health Rep 1994, 109:86-92.

33. Magnus JH, Joakimsen RM, Berntsen GK, Tollan A, Soogaard AJ: What do Norwegian women and men know about osteoporosis? Osteoporosis Int 1996, 6:31-36.

34. Hreshchyshyn MM, Hopkins A, Zylstra S, Anbar M: Associations of parity, breastfeeding and birth control pills with lumbar spine and femoral neck bone densities. Am J Obstet Gynecol I988, 159:318-322.

35. Kesson CM, Morris N, McCutcheon A: Generalized osteoporosis in old age. Ann Rheum Dis 1947, 6:146-61. 
36. Lissner L, Bengtssson C, Hansson T: Bone mineral contents in relation to lactation history in pre-and postmenopausal women. Calcify Tissue Int 1991, 48:319-25.

37. Goldsmith NF, Johnson JO: Bone mineral: effects of oral contraceptives, pregnancy, and lactation. J Bone Joint Surg 1975, 57A:657-668.

38. Atkinson PJ, West RR: Loss of skeletal calcium in lactating women. J Obstet Gynaecol Br Common 1970, 77:555-60.

39. Lamke B, Brundin J, Moberg P: Changes of bone mineral content during pregnancy and lactation. Acta Obstet Gynecol Scand 1977, 56:217-219.

40. Hayslip CC, Klein TA, Wray HL, Duncan WE: The effects of lactation on bone mineral content in healthy postmenopausal women. Obstet Gynecol 1989, 73:588-92.

41. Wardlaw G, Pike AM: The effect of lactation on peak adult shaft andultra-distal forearm bone mass in women. Am J Clin Nutr 1986, 44:283-6.

\section{Pre-publication history}

The pre-publication history for this paper can be accessed here:

http://www.biomedcentral.com/1471-2296/5/18/prepub

Publish with Bio Med Central and every scientist can read your work free of charge

"BioMed Central will be the most significant development for disseminating the results of biomedical research in our lifetime. "

Sir Paul Nurse, Cancer Research UK

Your research papers will be:

- available free of charge to the entire biomedical community

- peer reviewed and published immediately upon acceptance

- cited in PubMed and archived on PubMed Central

- yours - you keep the copyright 